\title{
Comparison of icodextrin and glucose solutions for long- dwell exchange in continuous ambulatory peritoneal dialysis patients; a preliminary study
}

\author{
Fatemeh Yaghoubi $^{1 \oplus}$, Sudabeh Alatab ${ }^{2^{*}}{ }^{\oplus}$, Iraj Najafi $^{1}$ \\ ${ }^{1}$ Nephrology Research Center, Shariati Hospital, Tehran University of Medical Sciences, Tehran, Iran \\ ${ }^{2}$ Urology Research Center, Sina Hospital, Tehran University of Medical Sciences, Tehran, Iran
}

\section{A R T I C L E I N F O}

Article Type:

Original

\section{Article History:}

Received: 7 March 2018

Accepted: 10 October 2018

Published online: 5 November 2018

\section{Keywords:}

Peritoneal dialysis

Ultrafiltration failure

Peritoneal equilibrium test

Icodextrin

Creatinine clearance

Ultrafiltration

\begin{abstract}
A B S T RA C T
Introduction: Icodextrin is widely used in peritoneal dialysis (PD) and several clinical observations suggest the superiority of icodextrin compared with $4.25 \%$ dextrose in optimizing peritoneal ultrafiltration (UF). However this solution has been introduced to our PD centers over the last two years.

Objectives: In this study we aimed to evaluate the effects of employment of this solution in our PD patients.

Patients and Methods: The study was carried out in two Iranian PD centers (Shafa and Shariati centers). We included 29 established patients ( 12 male and 17 female, mean age 58.9 \pm 11.1 years) who used icodextrin for the long-dwell exchange for last 6 months. Clinical data were collected at baseline and 6 months after icodextrin administration.

Results: When the data between baseline and after 6 months of icodextrin administration was evaluated, we found no significant change in evaluated parameters including 24 hours UF, 24 hours urine volume, membrane transport type, Kt/V and creatinine clearance was observed.

Conclusion: Icodextrin for the long-dwell exchange did not improve the creatinine clearance despite producing, a non-significant increase in 24-hour UF, after 6 months. Due to low proportion of patients and high inter-patients variability we cannot reach a robust conclusion. Studies with bigger sample size involving several PD centers are necessary to further address this subject.
\end{abstract}

Implication for health policy/practice/research/medical education:

In recent years, more biocompatible peritoneal dialysis $(\mathrm{PD})$ solutions such as icodextrin are being developed to produce sustained positive net ultrafiltration over long dwells while reducing the glucose load and therefore causing potentially less damage to peritoneal cells compared to solutions containing $4.25 \%$ dextrose. In our country, it is not a long-time that icodextrin has been introduced to our PD patients. Our data concerning the inability of icodextrin to improve the creatinine clearance should be interpreted with caution as our sample size was small. This study could be an initiation for performing other studies with larger sample size to justify the use of this solution in our country.

Please cite this paper as: Yaghoubi F, Alatab S, Najafi I. Comparison of icodextrin and glucose solutions for long-dwell exchange in continuous ambulatory peritoneal dialysis patients; a preliminary study. J Renal Inj Prev. 2019;8(2):65-70. DOI: $10.15171 /$ jrip.2019.13.

\section{Introduction}

Chronic kidney disease (CKD) is a worldwide public health problem that affects approximately $7 \%$ of the population worldwide. Progression of CKD to stage V leads to endstage renal disease (ESRD) in which patients need dialysis or kidney transplant in order to survive. The incidence of ESRD starts to decrease in developed countries in recent years, which probably caused by increased awareness of CKD (at least partly). However, no such change is seen in developing countries or minority populations (1). Currently, worldwide, more than two million people require renal replacement therapy to sustain life. Continuous ambulatory peritoneal dialysis (CAPD) is one of the kidney replacement therapy that has been applied worldwide for more than 25 years in ESRD patients (2). In some countries such as Hong Kong and Singapore 
peritoneal dialysis (PD) is first-line renal replacement therapy for majority of ESRD individuals (3). In Iran an increase in the number of patients receiving CAPD has been observed over time (4). According to the last published data from Iranian peritoneal Dialysis Registry (IPDR) in 2010, 4.1\% of Iranian ESRD patients are on CAPD (4). As a treatment option, PD has some advantageous aspects such as clinical effectiveness, social circumstances, and tolerance by patient. Some observations support the better survival of patients during the first years of renal replacement therapy when $\mathrm{PD}$ rather than hemodialysis is used $(5,6)$. However, there is substantial patients' dropout due to infectious complications and mechanical or ultrafiltration failure (UFF) $(7,8)$. Continuous exposure of the peritoneum to bioincompatible PD solutions provokes activation of various inflammatory, fibrogenic and angiogenic cytokines, which their interaction leads to progressive detachment of the mesothelial cell layer, submesothelial extracellular matrix deposition and fibrosis, and extensive vasculopathy and neoangiogenesis and ultimately loss of peritoneal membrane function and UFF development (9). These alterations may eventually cause encapsulating peritoneal sclerosis which is a rare but dangerous complication of PD.

The morphological and functional alterations of the peritoneal membrane and UFF in CAPD patients might be caused by non-physiological composition of conventional glucose-based solutions including the high glucose concentration with its consequent high osmolarity, the existence of glucose degradation products (GDPs) formed throughout the heat sterilization process, and low $\mathrm{pH}$ and high concentration of lactate buffer which is known to be harmful for the peritoneal membrane (9-11). To overcome these problems, over the past two decades, newer more biocompatible PD solutions have been developed. One commercially available PD solution alternative is icodextrin (Extraneal ${ }^{\circledR} 7.5 \%$, Baxter, and Deerfield, IL, USA) which is an iso-osmolar (284 mOsm/ $\mathrm{kg}$ ) mixture of glucose polymers with different molecular weights that allows constant linear ultrafiltration. The ultrafiltration capacity of a 7.5\% icodextrin solution, used for the 8 hours to 12 hours overnight dwell in CAPD patients is lengthier but longer than $3.86 \%$ glucose (12). Some studies have shown that icodextrin preserves ultrafiltration, particularly in patients with high rates of peritoneal transport (13). The rise in ultrafiltration has been associated with an increase in small-solute clearance $(13,14)$, an effect that made it probable to maintain hightransport and anuric patients for longer time on PD (15). In our country, this solution has been introduced to our PD centers over the last two years and to our knowledge, no study has been conducted yet to evaluate the effects of employment of this solution in our PD patients.

\section{Objectives}

In this study we evaluated the response to 6 months use of icodextrin solution in 12 hours nighttime dwell time by assessing the peritoneal transport characteristics before and after 6 months of icodextrin administration. The evaluated parameters included 24 hours ultrafiltration, 24 hours urine volume, $\mathrm{Kt} / \mathrm{V}$ total, $\mathrm{Kt} / \mathrm{V}$ residual, creatinine clearance total, creatinine clearance residual and membrane transport type.

\section{Patients and Methods}

\section{Participants and variables}

This retrospective study was conducted from June 2014 to June 2015 and included PD patients who were stable during at least 90 days before enrollment. The participants were selected from Shafa and Shariati PD centers, (Tehran, Iran). All patients from these two centers who aged $\geq 18$ years and used icodextrin for a minimum of 6 months were included in the study. Exclusion criteria included; documented anaphylaxis with icodextrin and ongoing infection or known infection within the last 30 days.

The reasons for change the regular $\mathrm{PD}$ solutions to icodextrin were; having resistance hypertension, fluid overload and edema, UFF and being high membrane transport type. Icodextrin was administered as one regiment of night dwell dialysate (12 hours). Peritoneal equilibration test (PET) and clinical and laboratory examinations were performed at beginning and after 6 months of icodextrin administration. PET was performed with the Adequest software package according to the manufacturer's guidelines (Baxter Healthcare Corp., McGaw Park, IL, USA).

After an overnight dwell, we assessed drained volume and levels of creatinine, and urea in the dialysate, blood samples were drawn and immediately sent for analysis. On the basis of measured effluent and urine volume and creatinine and urea concentrations, the creatinine and urea clearances were calculated. Ultrafiltration was calculated as drainage volume minus instillation volume. A standard PET was performed at baseline and 6 months after icodextrin administration. The ratio of creatinine in the dialysate to plasma after a standardized 4hours dwell (D/Pcr) was used to classify membrane transport type (16).

\section{Ethical issues}

The research followed the tenets of the Declaration of Helsinki. Informed consent was obtained. The research was approved by the ethical committee of Tehran University of Medical Sciences (Ethical code \# IR.TUMS. DDRI.REC.1396.15).

\section{Statistical analysis}

Results were presented as mean \pm standard deviation (SD) and were summarized by frequency (percentage). Continuous variables were compared using $t$ test or Mann-Whitney U test whenever the data did not appear to have normal distribution or when the assumption of 
equal variances was violated across the study groups. Categorical variables were, on the other hand, compared using chi-square test. The change in chemical biomarkers after treatment compared with the baseline values was assessed using the paired $t$ test or Wilcoxon test. For the statistical analysis, the statistical software SPSS version 16.0 for Windows (SPSS Inc., Chicago, IL) was used and $\mathrm{P}$ values of 0.05 or less were considered statistically significant.

\section{Results}

The demographics of the 29 studied patients are shown in Table 1 . Their mean age was $58.9 \pm 11.1$ years. There were 12 males (41.4\%) and 17 females (58.6\%). Mean duration of PD was 61.2 months. The underlying renal disease was diabetic nephropathy in 15 (51.7\%), chronic glomerulonephritis in $3(10.3 \%)$, hypertension in 5 (17.3\%), polycystic kidney disease in one $(3.4 \%)$, and other reasons in $5(17.3 \%)$ patients.

When the data between baseline and after 6 months of icodextrin administration was evaluated, we found that mean arterial blood pressure significantly decreased after icodextrin treatment (105.3 mm Hg vs $93.5 \mathrm{~mm} \mathrm{Hg}$ ), however no significant change in the other evaluated parameters was observed. In 2 patients no change in 24-hour urine volume was observed while 21 patients

Table 1. Baseline data of patients

\begin{tabular}{|c|c|}
\hline Characteristic & Value \\
\hline Mean age (y) (SD, min-max) & $58.9(11.1,40-83)$ \\
\hline Male/ female (\%) & $12 / 17(41.4 \% / 58.6 \%)$ \\
\hline Mean arterial pressure, $\mathrm{mm} \mathrm{Hg} \mathrm{(SD)}$ & $147.6(29.2)$ \\
\hline Body mass index, $\mathrm{kg} / \mathrm{m}^{2}(\mathrm{SD})$ & $28.2(4.7)$ \\
\hline \multicolumn{2}{|l|}{ Cause of ESRD (\%) } \\
\hline Diabetic nephropathy & $15(51.7)$ \\
\hline Hypertensive nephropathy & $5(17.3)$ \\
\hline Glomerulonephritis & $3(10.3)$ \\
\hline Polycystic kidney disease & $1(3.4)$ \\
\hline Others & $5(17.3)$ \\
\hline \multicolumn{2}{|l|}{ Cause for icodextrin administration (\%) } \\
\hline Hypertension & $12(41.4)$ \\
\hline Edema & $21(72.4)$ \\
\hline Ultrafiltration failure & $16(55.2)$ \\
\hline High membrane transport type & $15(51.7)$ \\
\hline \multicolumn{2}{|l|}{ No. of causes for icodextrin administration } \\
\hline 1 & $5(17.2)$ \\
\hline 2 & $14(48.3)$ \\
\hline$\geq 3$ & $10(34.5)$ \\
\hline Mean dialysis time, month (SD) (min-max) & $61.2(77.4)(8-439)$ \\
\hline Angiotensin-converting-enzyme inhibitor (\%) & $4(13.8)$ \\
\hline Angiotensin-receptor blockers (\%) & $23(79.3)$ \\
\hline Calcium channel blocker (\%) & $13(44.8)$ \\
\hline Loop diuretic $(\%)$ & $15(48.3)$ \\
\hline K sparing diuretic (\%) & $2(6.9)$ \\
\hline
\end{tabular}

experienced a decrease and 6 patients had an increase in their urine volume $(P=\mathrm{NS})$. Of 14 patients who had high membrane transport type in baseline, 11 patients stayed without change after icodextrin, while 3 patients experienced a membrane transport type change from high to high average. Three out of nine patients with high average membrane transport type in baseline presented with high membrane transport type at the end of study. Tables 2 and 3 compare the characteristics of peritoneal permeability and also laboratory changes after 6 months of icodextrin administration.

\section{Discussion}

The administration of icodextrin has been characterized as one of the major achievements in PD. This solution is a clear, colorless peritoneal dialysis solution comprising icodextrin as the primary osmotic ingredient at a concentration of $7.5 \%$ in an electrolyte solution with $40 \mathrm{mEq} / \mathrm{L}$ lactate. Icodextrin is indicated to improve ultrafiltration and clearance of creatinine and urea nitrogen in patients with high average or greater transport characteristics. Several studies showed the benefits of icodextrin such as: attenuation of total glucose load, achieving higher UF than that obtained by hypertonic glucose solution, and better control of fluid balance and the overall message of these studies is that icodextrin is superior in creatinine clearance $(\mathrm{CrCl})$ and $\mathrm{UF}$ to solutions containing high glucose concentration (13,17-19).

Table 2. Patients' characteristics before and 6 months after icodextrin administration

\begin{tabular}{|c|c|c|c|}
\hline Characteristics & Pre-icodextrin & Post-icodextrin & $P$ \\
\hline Edema & & & NS \\
\hline No edema, No. (\%) & $8(27.6)$ & $8(27.6)$ & \\
\hline+1 & $0(0)$ & $13(44.8)$ & \\
\hline+2 & $4(13.8)$ & $8(27.6)$ & \\
\hline+3 & $17(58.6)$ & $0(0)$ & \\
\hline $\begin{array}{l}\text { Mean arterial pressure, } \\
\mathrm{mm} \mathrm{Hg} \text {, mean (SD) }\end{array}$ & $105.3(17.2)$ & $93.5(11.3)$ & 0.001 \\
\hline $\begin{array}{l}\text { 24-h urine volume, } \mathrm{mL} \text {, } \\
\text { mean (SD) }\end{array}$ & $472.4(613)$ & $346.6(369.3)$ & NS \\
\hline $\begin{array}{l}\text { UF, mL, mean (SD) ( } 24 \\
\text { or not) }\end{array}$ & 992.1 (544.9) & $1238(763.3)$ & NS \\
\hline \multicolumn{4}{|l|}{ Membrane transport type } \\
\hline High & $14(58.3)$ & $14(58.3)$ & \\
\hline High average & $9(37.5)$ & $10(41.7)$ & \\
\hline Low average & $0(0)$ & & \\
\hline Low & $1(4.2)$ & & \\
\hline Kt/V, mean (SD) & & & NS \\
\hline Total & $1.9(0.5)$ & $1.8(0.4)$ & \\
\hline Residual & $0.3(0.4)$ & $0.2(0.2)$ & \\
\hline $\begin{array}{l}\text { Creatinine clearance, } c c / \\
\text { min, mean (SD) }\end{array}$ & & & NS \\
\hline Total & $62.1(16.5)$ & $61.7(10.3)$ & \\
\hline Residual & $12.5(15.5)$ & $10.5(11.8)$ & \\
\hline
\end{tabular}

UF, ultrafiltration; BP: blood pressure; NS, not significant.

Data are presented as mean \pm SD. $P<0.05$ is considered significant. 
Table 3. Biochemical characteristics of patients before and 6 months after icodextrin usage

\begin{tabular}{|c|c|c|c|}
\hline Characteristics & Pre-icodextrin & Post-icodextrin & $P$ \\
\hline $\mathrm{Hb}, \mathrm{g} / \mathrm{dL}$ & $10.8(1.8)$ & $11(2)$ & NS \\
\hline Ferritin, $\mathrm{ng} / \mathrm{mL}$ & $532.3(345)$ & $557.5(332.4)$ & NS \\
\hline TIBC, $\mu \mathrm{g} / \mathrm{dL}$ & $283(85.2)$ & 300.1 (91.9) & NS \\
\hline $\mathrm{Ca}, \mathrm{mg} / \mathrm{dL}$ & $9.2(1.3)$ & $9.6(0.8)$ & NS \\
\hline Phosphorus, mg/dL & $4.7(1.5)$ & $4.7(1.8)$ & NS \\
\hline iPTH, pmol/L & 127.5 (129.9) & $114.3(102.2)$ & NS \\
\hline $\mathrm{Na}, \mathrm{mEq} / \mathrm{L}$ & $140.7(4.5)$ & $138.2(4.8)$ & NS \\
\hline $\mathrm{K}, \mathrm{mEq} / \mathrm{L}$ & $4.5(0.7)$ & $4.5(0.7)$ & NS \\
\hline TG, mg/dL & $165.3(90.7)$ & $209.2(168.2)$ & NS \\
\hline Cholesterol, mg/dL & 170.9 (35.7) & $167.6(47.8)$ & NS \\
\hline $\mathrm{HDL}-\mathrm{C}, \mathrm{mg} / \mathrm{dL}$ & $43.3(10.1)$ & 41.4 (11.9) & NS \\
\hline $\mathrm{LDL}-\mathrm{C}, \mathrm{mg} / \mathrm{dL}$ & $94.1(24.5)$ & $91.9(30.2)$ & NS \\
\hline $\mathrm{FBS}, \mathrm{mg} / \mathrm{dL}$ & $183.7(87.6)$ & $142.3(61.8)$ & NS \\
\hline Albumin, g/dL & $3.8(0.5)$ & $3.6(0.4)$ & NS \\
\hline ESR & $56.3(27.0)$ & $53.3(30.5)$ & NS \\
\hline CRP, mg/L & $1.3(0.5)$ & $1.4(0.9)$ & NS \\
\hline $\begin{array}{l}\text { 25-hydroxyvitamin D, } \\
\mathrm{nmol} / \mathrm{L}\end{array}$ & $17.7(9.1)$ & $20.3(16.1)$ & NS \\
\hline
\end{tabular}

TIBC, Total iron binding capacity; iPTH, intact parathyroid hormone; TG, triglyceride; HDL, high-density lipoprotein; LDL, low-density lipoprotein; FBS, Fasting blood sugar; ESR, erythrocyte sedimentation rate; CRP, C-reactive protein; NS: not significant.

Data are presented as mean \pm SD.

$P<0.05$ is considered significant.

In our country, it is not a long-time that icodextrin has been introduced to our PD patients and there is spare data regarding the performance of this compound in our CAPD patients.

Here in this study we evaluated the effects of 6 months administration of icodextrin in 12 hours night dwell time on membrane transport characteristics in a small number of CAPD patients and found that no significant changes in small solute transport and ultrafiltration occurred in these patients.

Our patients had a mean of $992.1 \mathrm{~mL}$ of UF before icodextrin administration. After 6 months of treatment, we observed an increase in UF volume $(1238 \mathrm{~mL})$ which although was not significant but revealed a $25 \%$ increase in UF. A randomized, double-blind, perspective control study performed in stable prevalent CAPD patients to compare the effects of $7.5 \%$ icodextrin or $2.5 \%$ glucose solution for 4 weeks on different peritoneal characteristics showed that UF almost doubled after 4 weeks of icodextrin treatment (20). Another multicenter randomized, doubleblind trial that conducted in 92 patients for comparing icodextrin and $4.25 \%$ dextrose during the long-dwell of automated PD showed that net UF significantly increased from 141.6 to $505.8 \mathrm{~mL}$ at week 1 and to $540.2 \mathrm{~mL}$ at week 2 (13). In our study we have a nonsignificant increase in UF after 6 months of icodextrin treatment. One reason that we did not see a significant change in UF might be related to the mode that UF was measured. As in our study we measured the 24 hours collected UF, but in mentioned studies, the UF was measured in the morning after the night dwell. Similarly, Posthuma and colleagues measured both daytime and 24 hours UF and found that after icodextrin treatment, daytime UF volumes increased significantly $(-117 \mathrm{~mL}$ to $268 \mathrm{~mL})$ while 24 hours UF increased but in a non-significant manner (816 to 1196 mL) (21).

One observation in our study was the absence of improvement in both total and residual creatinine clearance after 6 months of icodextrin treatment. A meta-analysis of randomized controlled trials performed for comparison of icodextrin and glucose solutions, for long-dwell exchange. This meta-analysis revealed that compared to the glucose group, peritoneal clearances of creatinine and urea nitrogen were increased significantly in group received icodextrin (22). However the study conducted by Posthuma et al found no significant changes in urea and creatinine clearance after icodextrin (21).

A randomized trial of 41 incident PD patients followed for 2 years showed that peritoneal small solute transport increased similarly in both standard solution and the icodextrin group (23).

Moreover two recent randomized trials with longer follow-up periods have shown that amount of decline of residual renal function among patients receiving icodextrin is either equal to greater than the decline in those receiving standard solutions $(23,24)$. However, meta-analysis of randomized controlled trials showed no effect of icodextrin on residual renal function (22). The most likely provided explanation for a potential icodextrin-related decline in residual renal function is a reduction in extracellular fluid volume owing to increased peritoneal ultrafiltration $(24,25)$.

Several factors might have contributed to our results in this study. One might be the low number of patients and also the high percentage of complicated patients in our study as most of our patients had more than one reason to administer icodextrin. This high degree of complication might have masked the net effects of icodextrin on creatinine clearance. Another reason might be related to high inter-patients variability in diuresis and in residual renal function in our study as icodextrin might affects differently the patients with different baseline volume status. For example, if, icodextrin is administered to a euvolemic patient, the increase in UF may lead to a decrease in renal perfusion and a decline in residual renal function (26).

\section{Conclusion}

This study to our knowledge is the first study in our country that evaluates the effects of 6 months treatment with icodextrin in a limited number of CAPD patients. We demonstrated that icodextrin for the long-dwell 
exchange did not improve the creatinine clearance despite producing, although non-significant, additional 24 hours UF, after 6 months. The strength of this study is its novelty in our country. However our limitation is the low number of patients and also not having a good and comparable control group. Due to low proportion of patients and high inter-patients variability we cannot reach a robust conclusion regarding the effects of icodextrin in CAPD patients. Studies with bigger sample size involving several PD centers are necessary to further address this subject.

\section{Limitations of our study}

This is a preliminary study conducted in a relatively small sample size and conducted in a limited time. Thus these results require further investigations.

\section{Acknowledgments}

We would like to thank the Research Development Center of Shariati Hospital, especially from Dr. Fatemeh Esfahanian that helped us in the analysis process of obtained data.

\section{Authors' contribution}

FY; conception and design of the study, collection and assembly of data, data analysis and interpretation, final approval of the manuscript. SA; manuscript writing, interpretation of data, acting as corresponding author, final approval of the manuscript. IN; substantial contribution to conception and design of the study, final approval of the manuscript.

\section{Conflicts of interest}

The authors declared no competing interests.

\section{Ethical considerations}

Ethical issues (including plagiarism, data fabrication, double publication) have been completely observed by the authors.

\section{Funding/Support}

This study was supported by a research grant from Tehran University of Medical Sciences.

\section{References}

1. Grassmann A, Gioberge S, Moeller S, Brown G. End-stage renal disease: global demographics in 2005 and observed trends. Artif Organs. 2006;30:895-7. doi:10.1111/j.15251594.2006.00321.x.

2. Couser WG, Remuzzi G, Mendis S, Tonelli M. The contribution of chronic kidney disease to the global burden of major noncommunicable diseases. Kidney Int. 2011;80:1258-70. doi: 10.1038/ki.2011.368.

3. Blake PG. Peritoneal dialysis in Asia: an external perspective. Perit Dial Int. 2002; 22:258-64

4. Najafi I, Alatab S, Atabak S, Majelan NN, Sanadgol H, Makhdoomi K, et al. Seventeen years' experience of peritoneal dialysis in Iran: first official report of the Iranian peritoneal dialysis registry. Perit Dial Int. 2014;34:636-42. doi: $\quad 10.3747 /$ pdi.2012.00054.

5. Selgas R, Cirugeda A, Fernandez-Perpén A, SánchezTomero JA, Barril G, Alvarez V, et al. Comparisons of hemodialysis and CAPD in patients over 65 years of age: a meta-analysis. Int Urol Nephrol. 2001;33:259-64.

6. Termorshuizen F, Korevaar JC, Dekker FW, Van Manen JG, Boeschoten EW, Krediet RT. Hemodialysis and peritoneal dialysis: comparison of adjusted mortality rates according to the duration of dialysis: analysis of The Netherlands Cooperative Study on the Adequacy of Dialysis. J Am Soc Nephrol. 2003;14:2851-60.

7. Smit W, Schouten N, van den Berg N, Langedijk MJ, Struijk DG, Krediet RT. Analysis of the prevalence and causes of ultrafiltration failure during long-term peritoneal dialysis: a cross-sectional study. Perit Dial Int. 2004;24:562-70.

8. Bilgic A, Sezer S, Ozdemir FN, Akgul A, Arat Z, Haberal M. Clinical outcome after transfer from peritoneal dialysis to hemodialysis. Adv Perit Dial. 2006;22:94-8.

9. Williams JD, Craig KJ, Topley N, Von Ruhland C, Fallon M, Newman GR, et al. Morphologic changes in the peritoneal membrane of patients with renal disease. J Am Soc Nephrol. 2002;13:470-9.

10. Catalan MP, Reyero A, Egido J, Ortiz A. Acceleration of neutrophil apoptosis by glucose-containing peritoneal dialysis solutions: role of caspases. J Am Soc Nephrol. 2001;12:2442-9.

11. Ha H, Yu MR, Choi HN, Cha MK, Kang HS, Kim MH, et al. Effects of conventional and new peritoneal dialysis solutions on human peritoneal mesothelial cell viability and proliferation. Perit Dial Int. 2000;20:S10-8.

12. Mistry CD, Gokal R, Peers E. A randomized multicenter clinical trial comparing isosmolar icodextrin with hyperosmolar glucose solutions in CAPD. MIDAS Study Group. Multicenter Investigation of Icodextrin in Ambulatory Peritoneal Dialysis. Kidney Int. 1994;46:496503. doi: 10.1038/ki.1994.300.

13. Finkelstein F, Healy H, Abu-Alfa A, Ahmad S, Brown F, Gehr T, et al. Superiority of Icodextrin compared with $4.25 \%$ dextrose for peritoneal ultrafiltration. J Am Soc Nephrol. 2005;16:546-54. doi: 10.1681/ASN.2004090793.

14. Woodrow G, Stables G, Oldroyd B, Gibson J, Turney JH, Brownjohn AM. Comparison of Icodextrin and glucose solutions for the daytime dwell in automated peritoneal dialysis. Nephrol Dial Transplant. 1999;14:1530-5.

15. Davies SJ, Brown EA, Frandsen NE, Rodrigues AS, Rodriguez-Carmona A, Vychytil A, et al. Longitudinal membrane function in functionally anuric patients treated with APD: data from EAPOS on the effects of glucose and icodextrin prescription. Kidney Int. 2005;67:1609-15. doi:10.1111/j.1523-1755.2005.00243.x.

16. Pannekeet MM, Imholz AL, Struijk DG, Koomen GC, Langedijk MJ, Schouten N, et al. The standard peritoneal permeability analysis: a tool for the assessment of peritoneal permeability characteristics in CAPD patients. Kidney Int. 1995;48:866-75. doi: 10.1038/ki.1995.363.

17. Wolfson M, Piraino B, Hamburger RJ, Morton AR. A randomized controlled trial to evaluate the efficacy and safety of Icodextrin in peritoneal dialysis. Am J Kidney Dis. 2002;40:1055-65. doi:10.1053/ajkd.2002.36344. 
18. Nakamoto H, Babazono T, Kasai K, Kuriyama S, Sugimoto T, Nakayama M, et al. Successful use of icodextrin in elderly patients on continuous ambulatory peritoneal dialysis. Adv Perit Dial. 2005;21:168-74.

19. Hiramatsu T, Furuta S, Kakuta H. Favorable changes in lipid metabolism and cardiovascular parameters after Icodextrin use in peritoneal dialysis patients. Adv Perit Dial. 2007;23:58-61.

20. Lin A, Qian J, Li X, Yu X, Liu W, Sun Y, et al. Randomized controlled trial of icodextrin versus glucose containing peritoneal dialysis fluid. Clin J Am Soc Nephrol. 2009;4:1799-804. doi: 10.2215/CJN.02950509.

21. Posthuma N, ter Wee PM, Donker AJ, Oe PL, Peers EM, Verbrugh HA. Assessment of the effectiveness, safety, and biocompatibility of Icodextrin in automated peritoneal dialysis. The Dextrin in APD in Amsterdam (DIANA) Group. Perit Dial Int. 2000;20:S106-13.

22. Qi H, Xu C, Yan H, Ma J. Comparison of icodextrin and glucose solutions for long dwell exchange in peritoneal dialysis: a meta-analysis of randomized controlled trials. Perit Dial Int. 2011;3:179-88. doi: 10.3747/pdi.2009.00264.
23. Takatori Y, Akagi S, Sugiyama H, Inoue J, Kojo S, Morinaga $\mathrm{H}$, et al. Icodextrin increases technique survival rate in peritoneal dialysis patients with diabetic nephropathy by improving body fluid management: a randomized controlled trial. Clin J Am Soc Nephrol. 2011;6:1337-44. doi: $10.2215 /$ CJN.10041110.

24. Paniagua R, Ventura MD, Avila-Díaz M, Cisneros A, Vicenté-Martínez M, Furlong MD, et al. Icodextrin improves metabolic and fluid management in high and high-average transport diabetic patients. Perit Dial Int. 2009; 29:422-32.

25. Davies SJ, Garcia Lopez E, Woodrow G, Donovan K, Plum J, Williams P, et al. Longitudinal relationships between fluid status, inflammation, urine volume and plasma metabolites of Icodextrin in patients randomized to glucose or Icodextrin for the long exchange. Nephrol Dial Transplant. 2008;23: 2982-8. doi: 10.1093/ndt/gfn176.

26. Jansen MA, Hart AA, Korevaar JC, Dekker FW, Boeschoten EW, Krediet RT. Predictors of the rate of decline of residual renal function in incident dialysis patients. Kidney Int. 2002;62:1046-53. doi: 10.1046/j.1523-1755.2002.00505.x.

Copyright (C) 2019 The Author(s); Published by Nickan Research Institute. This is an open-access article distributed under the terms of the Creative Commons Attribution License (http://creativecommons.org/licenses/by/4.0), which permits unrestricted use, distribution, and reproduction in any medium, provided the original work is properly cited. 